\title{
Role of ghrelin in modulation of S-nitrosylation- dependent Akt inactivation induced in salivary gland acinar cells by Porphyromonas gingivalis
}

\author{
Bronislaw L. Slomiany*, Amalia Slomiany \\ Research Center, University of Medicine and Dentistry of New Jersey, Newark, USA; *Corresponding Author: slomiabr@umdnj.edu
}

Received 23 August 2010; revised 8 October 2010; accepted 26 October 2010

\begin{abstract}
Ghrelin, a peptide hormone, newly identified in oral mucosal tissue, has emerged recently as a principal modulator of the inflammatory responses to bacterial infection through the regulation of nitric oxide synthase system. In this study, using rat sublingual salivary gland acinar cells, we report that lipopolysaccharide (LPS) of periodontopathic bacterium, $P$. gingivalis- induced enhancement in the activity of inducible nitric oxide synthase (iNOS) was associated with the suppression in Akt kinase activity and the impairment in constitutive (c) cNOS phosphorylation. Further, we show that the detrimental effect of the LPS on Akt activation, manifested in the kinase protein S-nitrosylation and a decrease in its phosphorylation at $\mathrm{Ser}^{473}$, was susceptible to suppression by iNOS inhibitor, 1400W. Moreover, we demonstrate that a peptide hormone, ghrelin, countered the LPSinduced changes in Akt activity and NOS system. This effect of ghrelin was reflected in the decreased in Akt S-nitrosylation and the increase in its phosphorylation at $\mathrm{Ser}^{473}$, as well as cNOS activation through phosphorylation. Our findings suggest that $P$. gingivalis-induced up-regulation in iNOS leads to Akt kinase inactivation through S-nitrosylation that impacts cNOS activation through phosphorylation. We also show that the countering effect of ghrelin on $P$. gingivalis-induced disturbances in Akt activation are manifested in a decrease in the kinase S-nitrosylation and the increase in its phosphorylation.
\end{abstract}

Keywords: P. Gingivalis; Salivary Gland; iNOS; Akt
S-Nitrosylation; cNOS Phosphorylation; Ghrelin

\section{INTRODUCTION}

Recent advances in understanding the nature of factors that influence the extent of mucosal inflammatory responses along the alimentary tract, including that of oral cavity, have brought to focus the importance of a peptide hormone, ghrelin [1-4]. This 28-amino acid peptide, initially isolated from the stomach [1,2], and more recently identified in oral mucosa, saliva and the acinar cells of salivary glands [3], has emerged as a principal modulator of the local inflammatory responses to bacterial infection through the regulation of nitric oxide synthase (NOS) system responsible for nitric oxide (NO) production [5-8].

$\mathrm{NO}$ is a short-lived signaling molecule that plays an important role in a variety of regulatory pathways that are of significance to cellular survival, integrity maintenance, and the extent of mucosal inflammatory involvement in response to bacterial challenge $[9,10]$. The physiological and pathophysiological implications of NO depend on its local concentration, the type of NOS isozyme involved in NO generation, substrate availability, and the enzyme compartmentalization with respect to protein target $[9,10]$. A low level of NO generated by membrane-associated constitutive nitric oxide synthase (cNOS) appears to access a pool of substrates that are of importance to the maintenance of normal physiological functions, including the regulation of apoptogenic signal propagation [7,10-12]. In contrast, a high output of NO generated by more distant cytosolic inducible nitric oxide synthase (iNOS) in response to proinflammatory cytokines and bacterial LPS, has been implicated in host response to sepsis and endotoxemia $[9,13]$. However, sustained iNOS activation associated with persistence of inflammatory stimulus, is known to have cytotoxic consequences reflected in transcriptional disturbances and the induction of apoptosis [9,11,12,14].

The signaling mechanism that underlies the regulation 
of NO by ghrelin involves the receptor (GHSR1a)- mediated activation of heterotrimeric $G$ protein-dependent pathway that results in signal propagation through a multiple network of protein kinases, including that of Akt kinase implicated in controlling the activity of NOS isozyme system $[6,7,15]$. The serine/threonine kinase Akt, also known as protein kinase B (PKB) or Akt/PKB, is a central player in the regulation apoptosis, cell cycle and metabolic pathways, host inflammatory responses, and signal transduction pathways activated by growth factors and insulin [16-18]. Activation of Akt in response to insulin or ghrelin occurs downstream of phosphoinositide 3-kinase (PI3K) and involves the generation of the lipid second messenger phosphatidylinositol-3,4,5triphosphate, which accumulates in the plasma membrane and serves as a recognition site for the $\mathrm{N}$-terminal PH (pleckstrin homology) domain of Akt $[17,18]$. The induced conformational changes in Akt result in the exposure to phosphorylation within the activation (A) loop at $\mathrm{Thr}^{308}$ and of $\mathrm{Ser}^{473}$ located within the HM (hydrophobic motif) region of the C-terminal regulatory domain of Akt $[17,18]$. Apparently, phosphorylation of the $\mathrm{Thr}^{308}$ in the activation loop and the Ser ${ }^{473}$ in the hydrophobic motif results in stabilization of the kinase domain in the active state, and hence is required for full activation of Akt $[17,19]$.

Moreover, recent studies indicate that the activity of Akt may be also regulated through S-nitrosylation at the kinase cysteine residues [16,20,21], and protein S-nitrosylation, with the involvement of NO generated by both constitutive and inducible forms of NOS system, is rapidly emerging as a signaling event of significance to a variety of biological processes [7-10]. Indeed, S-nitrosylation with the involvement of cNOS has been linked to the apoptogenic signal inhibition and the events of cytosolic phospholipase A2 activation, whereas the NO generated by iNOS has been implicated in S-nitrosylation of proteins involved in insulin signal transduction, and the reduced Akt activity in muscle cells of diabetic mouse [7,8,16,20-22]. Furthermore, protein modification through targeted S-nitrosylation is gaining recognition as an important post-translational event that, like protein modification through posttranslational phosphorylation, mediates a variety of signal transduction events propagated by NO [7-10,20-22].

As the oral mucosal inflammatory responses to periodontopathic bacterium, P. gingivalis, are characterized by the disturbances in NO production, and since Akt kinase plays a major role in the regulation of NOS isozyme system $[8,15,22,23]$, in this study we investigated the effect of P. gingivalis, key virulence factor, LPS, on the processes associated with the activation of kinase Akt in sublingual salivary gland acinar cells. Our data revealed that the LPS-induced up-regulation in iNOS leads to Akt inactivation through S-nitrosylation that exerts the detrimental effect on the processes of cNOS activation through phosphorylation. Moreover, we also revealed that the countering effect of ghrelin was manifested in a marked increase in Akt activity that correlated with a decrease in the kinase protein S-nitrosylation and the increase in its phosphorylation.

\section{MATERIALS AND METHODS}

\subsection{Salivary Gland Cell Incubation}

Freshly dissected rat sublingual salivary glands were trimmed of fat and connective tissue, and minced by passage through a 50 mesh metal grid [23]. The minces tissue was suspended in five volumes of ice-cold Dulbecco's modified (Gibco) Eagle's minimal essential medium (DMEM), supplemented with fungizone (50 $\mu \mathrm{g} / \mathrm{ml})$, penicillin $(50 \mathrm{U} / \mathrm{ml})$, streptomycin $(50 \mu \mathrm{g} / \mathrm{ml})$, and $10 \%$ fetal calf serum, and gently dispersed by trituration with a syringe, and settled by centrifugation [23]. Following rinsing, the cells were resuspended in the medium to a concentration of $2 \times 10^{7}$ cell $/ \mathrm{ml}$, transferred in $1 \mathrm{ml}$ aliquots to DMEM in culture dishes and incubated under $95 \% \mathrm{O}_{2}-5 \% \mathrm{CO}_{2}$ atmosphere at $37^{\circ} \mathrm{C}$ for $16 \mathrm{~h}$ in the presence of $0-200 \mathrm{ng} / \mathrm{ml}$ of $P$. gingivalis LPS [23]. In the experiments evaluating the effect of ghrelin (rat, Sigma), cNOS inhibitor, L-NAME, iNOS inhibitor, 1400W, Src inhibitor, Akt inhibitor, SH-5 (Calbiochem), and ascorbate (Sigma), the cells were first preincubated for $30 \mathrm{~min}$ with the indicated dose of the agent or vehicle before the addition of the LPS. The viability of cell preparations before and during the experimentation, assessed by Trypan blue dye exclusion assay [23], was greater than $98 \%$.

\subsection{P. gingivalis Lipopolysaccharide}

P. gingivalis used for LPS preparation was cultured from clinical isolates obtained from ATCC No. 33277 [24]. The bacterium was homogenized with liquid phenol-chloroform-petroleum ether, centrifuged, and the LPS contained in the supernatant was precipitated with water, washed with $80 \%$ phenol solution and dried with ether. The dry residue was dissolved in a small volume of water at $45^{\circ} \mathrm{C}$, centrifuged at $100,000 \mathrm{xg}$ for $4 \mathrm{~h}$, and the resulting LPS sediment subjected to lyophilization. The preparation was essentially free of nucleic acid and its protein content was less than $0.2 \%$.

\subsection{NO Production, and cNOS and iNOS Activity Assay}

NO production in the acinar cells was determined by 
measuring the stable NO metabolite, nitrite, accumulation in the culture medium using Griess reaction [25]. A $100 \mu \mathrm{l}$ of spent culture medium was incubated for 10 min with $0.1 \mathrm{ml}$ of Griess reagent and the absorbance was measured at $570 \mathrm{~nm}$. The concentration of nitrite was calculated with sodium nitrite as standard. The activity of cNOS and iNOS enzymes was measured by monitoring the conversion of $\mathrm{L}-[3 \mathrm{H}]$ arginine to L-[3H]citrulline using NOS-detect kit (Stratagene). The acinar cells from the control and experimental treatments were homogenized in a sample buffer containing either $10 \mathrm{mM}$ EDTA (for Ca2+ -independent iNOS) or $6 \mathrm{mM}$ $\mathrm{CaCl} 2$ (for $\mathrm{Ca} 2+$-dependent cNOS), and centrifuged [23]. The aliquots of the resulting supernatant were incubated for $30 \mathrm{~min}$ at $25^{\circ} \mathrm{C}$ in the presence of $50 \mu \mathrm{Ci} / \mathrm{ml}$ of $\mathrm{L}-[3 \mathrm{H}]$ arginine, $10 \mathrm{mM} \mathrm{NAPDH}, 5 \mu \mathrm{M}$ tetrahydrobiopterin, and $50 \mathrm{mM}$ Tis- $\mathrm{HCl}$ buffer, $\mathrm{pH}$ 7.4, in a final volume of $250 \mu \mathrm{l}$. Following addition of stop buffer and Dowex-50 W (Na+)resin, the mixtures were transferred to spin cups, centrifuged and the formed $\mathrm{L}-[3 \mathrm{H}]$ citrulline contained in the flow through was quantified by scintillation counting.

\subsection{Akt Activity Assay}

The kinase activity of Akt in sublingual salivary gland acinar cells was measured with the Akt Activity Kit (Calbiochem), by quantifying phosphorylation of a biotinylated peptide substrate (GRPRTSSFAEG). The cells were lysed in lysis buffer (20 mM Tris-HCl, pH 7.4, 150 $\mathrm{mM} \mathrm{NaCl}, 10 \%$ glycerol, $1 \%$ Triton $\mathrm{X}-100,1 \%$ deoxycholate, $2 \mathrm{mM}$ EDTA, $1 \mathrm{mM}$ sodium orthovanadate, 1 $\mathrm{mM}$ PAF, and $1 \mathrm{mM} \mathrm{NaF}$ ), containing protease inhibitor cocktail (Sigma), at $4^{\circ} \mathrm{C}$ for $30 \mathrm{~min}$, centrifuged at $14,000 \mathrm{x} g$ for $15 \mathrm{~min}$, and immunoprecipitated with anti-Akt antibody for $1 \mathrm{~h}$ at $4^{\circ} \mathrm{C}$. Protein $\mathrm{A} / \mathrm{G}$ agarose beads were then added for an additional $1 \mathrm{~h}$, and the immune complex was recovered by centrifugation and thoroughly washed with lysis buffer. The agarose beads were then suspended for $30 \mathrm{~min}$ at room temperature in the assay buffer, centrifuged, and the supernatants used for the Akt activity assay by following the manufacturer's instruction.

\subsection{Akt Phosphorylation Assay}

Measurement of the phosphorylation status of Akt in sublingual gland acinar cells was performed using Akt $\left(\mathrm{pThr}^{308}\right.$ ) and Akt (pSer $\left.{ }^{473}\right)$ ELISA kits (Calbiochem). The cells were lysed on ice for $30 \mathrm{~min}$ in lysis buffer (10 $\mathrm{mM}$ Tris-HCl, pH 7.4, $100 \mathrm{mM} \mathrm{NaCl,} 1 \mathrm{mM}$ EDTA, 1 mM EGTA, $1 \mathrm{mM}$ NaF, $2 \mathrm{mM}$ sodium orthovanadate, $1 \%$ Triton $\mathrm{X}-100,10 \%$ glycerol, $0.1 \%$ SDS, $0.5 \%$ deoxycholate, and $1 \mathrm{mM}$ PMSF), containing protease inhibi- tor cocktail, and centrifuged at $14,000 \mathrm{x}$ g for $15 \mathrm{~min}$. The supernatants diluted (1: 10) in standard diluent buffer were pipetted in $100 \mu$ l aliquots into wells containing immobilized capture antibody, and after washing the complex was reacted with antibody specific for Akt $\left(\mathrm{pThr}^{308}\right)$ or Akt $\left(\mathrm{pSer}^{473}\right)$. Following washing, the retained complex was labeled with horseradish peroxidase and probed with TMB reagent for spectrophotometric quantification at $450 \mathrm{~nm}$.

\subsection{Akt Protein S-Nitrosylation Assay}

Detection of Akt kinase S-nitrosylation in the acinar cells sublingual salivary gland was carried out using a biotin switch procedure for protein S-nitrosylation [26, 27]. The cells were treated with iNOS inhibitor, $1400 \mathrm{~W}$ (30 $\mu \mathrm{M})$ or ghrelin $(0.6 \mu \mathrm{g} / \mathrm{ml})$, and incubated for $16 \mathrm{~h}$ in the presence of $100 \mathrm{ng} / \mathrm{ml}$ of P. gingivalis LPS. Following centrifugation at 500xg for $5 \mathrm{~min}$, the recovered cells were lysed in $0.2 \mathrm{ml}$ of HEN lysis buffer (250 mM HEPES, $1 \mathrm{mM}$ EDTA, $0.1 \mathrm{mM}$ neocuprin, $\mathrm{pH}$ 7.7), and the unnitrosylated thiol groups were blocked with S-methyl methanethiosulfonate reagent at $50^{\circ} \mathrm{C}$ for 20 min [27]. The proteins were precipitated with acetone, resuspended in $0.2 \mathrm{ml}$ of HEN buffer containing $1 \%$ SDS, and subjected to targeted nitrothiol group reduction with sodium ascorbate $(100 \mathrm{mM})$. The free thiols were then labeled with biotin and the biotinylated proteins were recovered on streptavidin beads. The formed streptavidin bead-protein complex was washed with neutralization buffer, and the bound proteins were dissociated from streptavidin beads with $50 \mu$ l of elution buffer (20 mM HEPES, 100 mM NaCl, 1 mM EDTA, pH 7.7) containing 1\% 2-mercaptoethanol [27]. The obtained proteins were then analyzed by Western blotting.

\subsection{Immunoblotting Analysis}

The acinar cells from the control and experimental treatments were collected by centrifugation and resuspended for $30 \mathrm{~min}$ in ice-cold lysis buffer $(20 \mathrm{mM}$ Tris-HCl, pH 7.4, 150 mM NaCl, 10\% glycerol, 1\% Triton X-100, 2 mM EDTA, 1 mM sodium orthovanadate, 4 $\mathrm{mM}$ sodium pyrophosphate, $1 \mathrm{mM}$ PMSF, and $1 \mathrm{mM}$ $\mathrm{NaF}$ ), containing $1 \mu \mathrm{g} / \mathrm{ml}$ leupeptin and $1 \mu \mathrm{g} / \mathrm{ml}$ pepstatin [28]. Following brief sonication, the lysates were centrifuged at $12,000 \mathrm{~g}$ for $10 \mathrm{~min}$, and the supernatants were subjected to protein determination using BCA protein assay kit (Pierce). The samples, including those subjected to biotin switch procedure, were then resuspended in loading buffer, boiled for $5 \mathrm{~min}$, and subjected to SDS-PAGE using $40 \mu \mathrm{g}$ protein/lane. The separated proteins were transferred onto nitrocellulose membranes, blocked for $1 \mathrm{~h}$ with 5\% skim milk in Tris-buffered 
Tween (20 mM Tris-HCl, pH 7.4, $150 \mathrm{mM} \mathrm{NaCl,} \mathrm{0.1 \%}$ Tween-20), and probed with the antibody against phosphorylated protein at $4^{\circ} \mathrm{C}$ for $16 \mathrm{~h}$. After $1 \mathrm{~h}$ incubation with the horseradish peroxidase-conjugated secondary antibody, the phosphorylated proteins were revealed using an enhanced chemiluminescence. Membranes were stripped by incubation in $1 \mathrm{M}$ Tris- $\mathrm{HCl}(\mathrm{pH}$ 6.8), $10 \% \mathrm{SDS}$, and $10 \mathrm{mM}$ dithiotreitol for $30 \mathrm{~min}$ at $55^{\circ} \mathrm{C}$, and reprobed with antibody against total cNOS or Akt. Immunoblotting was performed using specific antibodies directed against cNOS and phospho-cNOS (Ser1179), and Akt, phospho-Akt (Ser ${ }^{473}$ ) (Calbiochem).

\subsection{Data Analysis}

All experiments were carried out using duplicate sampling, and the results are expressed as means \pm SD. Analysis of variance (ANOVA) followed by nonparametric Kruskal-Wallis test was used to determine significance and the significance level was set at $\mathrm{P}<0.05$.

\section{Results}

To investigate the role of Akt activation in the disturbances in NO production associated with oral mucosal inflammatory responses to periodontopathic bacterium, P. gingivalis, we used rat sublingual gland acinar cells exposed to the bacterium key virulence factor, LPS. We demonstrated that $\mathrm{P}$. gingivalis LPS caused a dose-dependent decrease in the acinar cell Akt activity, accompanied by the increase in NO production, so that at $100 \mu \mathrm{g} / \mathrm{ml}$ of the LPS the NO production showed a 15.1-fold increase, while the activity of Akt decreased by a 38\% (Figure 1). Furthermore, we revealed that that the inhibitory effect of the LPS on Akt activity was reflected in a $41 \%$ decrease in the kinase phosphorylation at $\mathrm{Ser}^{473}$, whereas the kinase phosphorylation at $\mathrm{Thr}^{308}$ was not affected (Figure 2).

Moreover, we found that preincubation with ghrelin lead to a concentration-dependent suppression of the LPS-induced effect on Akt activity and the extent of its protein phosphorylation at $\mathrm{Ser}^{473}$, which at $0.6 \mu \mathrm{g} / \mathrm{ml}$ resulted in a 2.2-fold increase the activity of Akt, and a 2.5-fold increase in its phosphorylation at $\mathrm{Ser}^{473}$ over that of the LPS (Figure 3). The Akt protein phosphorylation at $\mathrm{Thr}^{308}$, however, was not affected by ghrelin. We also determined that the disturbances in NO production elicited in the acinar cells by P. gingivalis LPS at $100 \mu \mathrm{g} / \mathrm{ml}$ were manifested a 26.4-fold up-regulation in iNOS activity and a 5.2-fold decrease in the activity of cNOS (Figure 4). However, while the activity of cNOS in the presence of $0.6 \mu \mathrm{g} / \mathrm{ml}$ ghrelin displayed an $80.4 \%$ increase over that of the LPS, the activity of iNOS in the presence of ghrelin showed a $94.3 \%$ decrease.

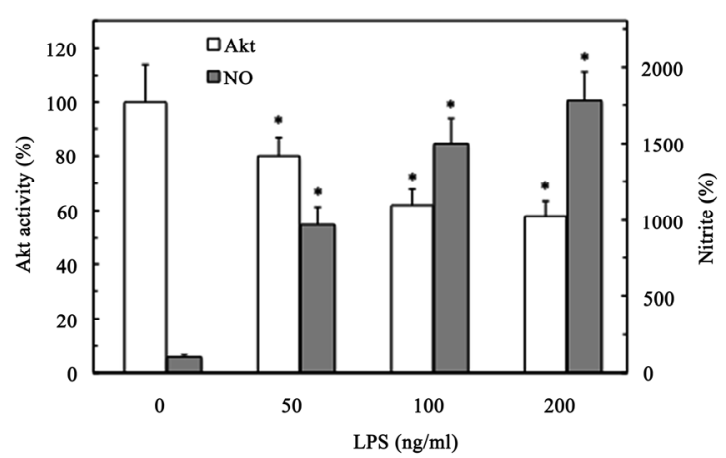

Figure 1. Effect of $P$. gingivalis LPS on Akt kinase activity and nitrite production in rat sublingual salivary gland acinar cells. The cells were treated with the indicated concentrations of the LPS and incubated for $16 \mathrm{~h}$. Values represent the means $\pm \mathrm{SD}$ of five experiments. $* P$ $<0.05$ compared with that of control (LPS -0 ).

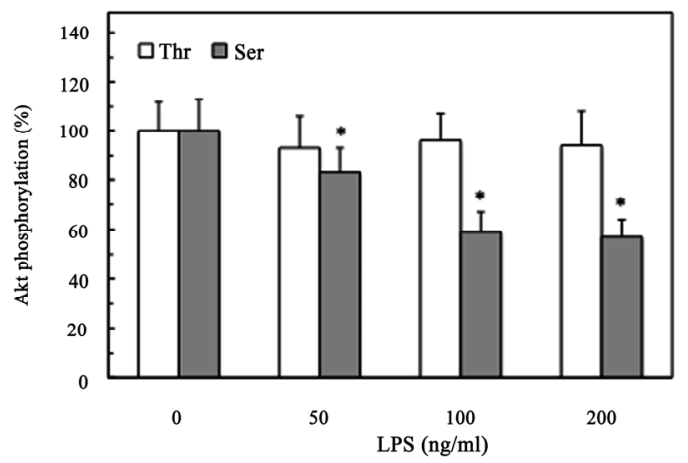

Figure 2. Effect of $P$. gingivalis LPS on Akt kinase threonine $\left(\mathrm{Thr}^{308}\right)$ and serine $\left(\mathrm{Ser}^{473}\right)$ phosphorylation in rat sublingual salivary gland acinar cells. The cells were treated with the indicated concentrations of the LPS and incubated for 16 h. $* P<0.05$ compared with that of control (LPS - 0).

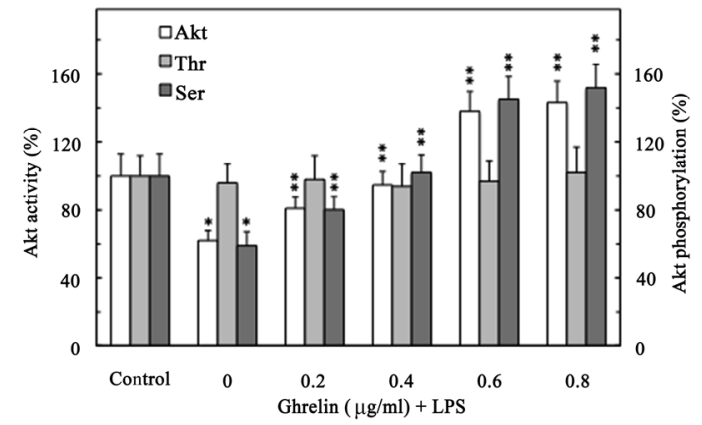

Figure 3. Effect of ghrelin on $P$. gingivalis LPS-induced changes in the acinar cell Akt activity and the phosphorylation at $\mathrm{Thr}^{308}$ and $\mathrm{Ser}^{473}$. The cells, preincubated with the indicated concentrations of ghrelin, were treated with the LPS at $100 \mathrm{ng} / \mathrm{ml}$ and incubated for $16 \mathrm{~h}$. Values represent the means \pm SD of five experiments. $* P<0.05$ compared with that of control. ${ }^{* *} P<0.05$ compared with that of LPS alone. 


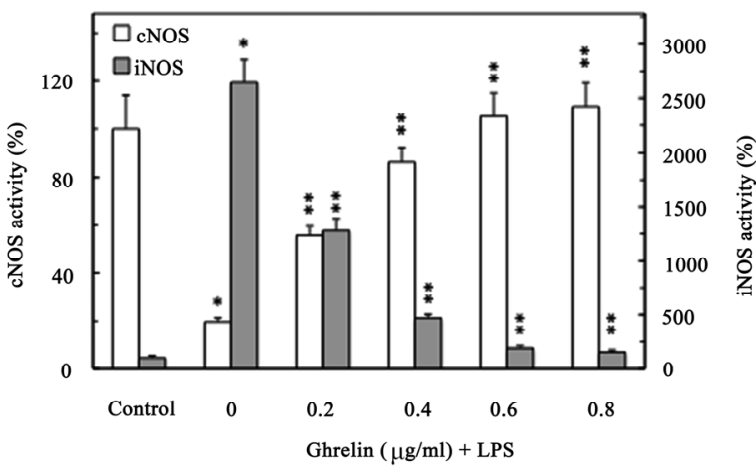

Figure 4. Effect of ghrelin on $P$. gingivalis LPS-induced changes in the expression of cNOS and iNOS activities in the salivary gland acinar cells. The cells, preincubated with the indicated concentrations of ghrelin, were treated with the LPS at $100 \mathrm{ng} / \mathrm{ml}$ and incubated for $16 \mathrm{~h}$. Values represent the means \pm SD of five experiments. ${ }^{*} P<0.05$ compared with that of control. ${ }^{* *} P<0.05$ compared with that of LPS alone.

To gain further leads into the involvement of Akt in the regulation of NOS system, we examined the influence of ghrelin on cNOS phosphorylation. For this, the acinar cells prior to incubation with the LPS were pretreated with ghrelin or ghrelin plus Akt inhibitor, SH-5, and the lysates were probed with antibodies directed against cNOS and phosphorylated cNOS (Ser1179). As shown in Figure 5, the LPS suppression in cNOS activity was associated with the inhibition in the enzyme phosphorylation, while the countering effect of ghrelin was reflected in a marked increase in the enzyme protein phosphorylation at Ser1179. Moreover, the suppression of ghrelin effect on cNOS phosphorylation was attained with Akt inhibitor, SH-5, thus supporting the role of Akt in ghrelin-induced cNOS activation through phosphorylation.

Hence, to reveal the nature of the detrimental effect of P. gingivalis LPS on the acinar cell Akt activity, we focused on the influence of $\mathrm{NO}$ on the events of Akt activation. For this, we analyzed the effects of cNOS inhibitor, L-NAME, and iNOS inhibitor, 1400W, as well as nitrosothiols reducing agent, ascorbate. We found that the detrimental effect of the LPS on the acinar cell Akt activity was subject to suppression not only by the pretreatment with ghrelin, but also displayed susceptibility to suppression by iNOS inhibitor, $1400 \mathrm{~W}$, and ascorbate, but not to the cNOS inhibitor, L-NAME (Figure 6). Furthermore, we observed that ascorbate as well as iNOS inhibitor, $1400 \mathrm{~W}$, produced amplification in the effect of ghrelin on Akt activity, thus suggesting that in addition to the activation through Ser/Thr phosphorylation, the Akt kinase activity may be also dependent upon its protein S-nitrosylation with the involvement of iNOS.

To assess further the course of events resulting in the

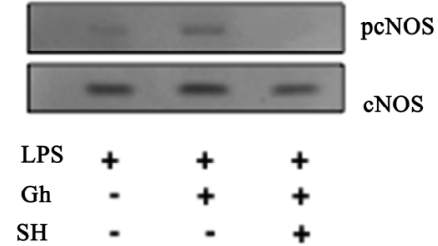

Figure 5. Effect of Akt kinase inhibitor, SH-5 (SH) on ghrelin-induced cNOS phosphorylation in the acinar cells exposed to $P$. gingivalis LPS. The cells were treated with ghrelin (Gh) at 0.6 $\mu \mathrm{g} / \mathrm{ml}$ or Akt inhibitor, SH-5 (30 $\mu \mathrm{M})+\mathrm{Gh}$, and incubated for $16 \mathrm{~h}$ in the presence of $100 \mathrm{ng} / \mathrm{ml}$ of the LPS. Cell lysates were resolved on SDS-PAGE, transferred to nitrocellulose and probed with phosphorylation specific cNOS pcNOS) antibody, and after stripping reprobed with anti-cNOS antibody. The immunoblots shown are representative of three experiments.

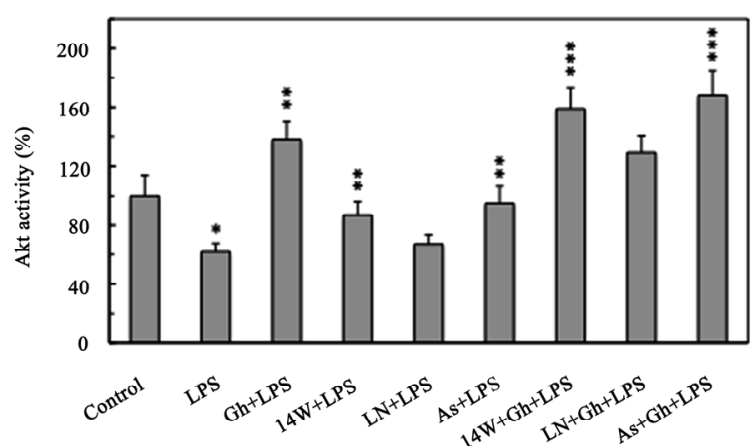

Figure 6. Effect of iNOS inhibitor, 1400W, cNOS inhibitor, L-NAME, and ascorbate on the ghrelin (Gh)-induced changes in Akt kinase activity in the acinar cell exposed to $P$. gingivalis LPS. The cells, preincubated with $30 \mu \mathrm{M}$ 1400W (14W), 200 $\mathrm{MM}$ L-NAME (LN), or $300 \mu \mathrm{M}$ ascorbate (As), were treated with $\mathrm{Gh}$ at $0.6 \mu \mathrm{g} / \mathrm{ml}$ ) and incubated for $16 \mathrm{~h}$ in the presence of $100 \mathrm{ng} / \mathrm{ml}$ LPS. Values represent the means \pm SD of five experiments. ${ }^{*} P<0.05$ compared with that of control. ${ }^{* *} P<0.05$ compared with that of LPS alone. ${ }^{* * * P}<0.05$ compared with that of Gh+LPS.

suppression of Akt activity by P. gingivalis LPS as well as to provide additional leads as to the mechanism of ghrelin countering effect, we examined the effect of cNOS and iNOS inhibitors, as well as nitrosothiols re-ducing agent, ascorbate, on Akt enzyme protein phosphorylation at $\mathrm{Thr}^{308} \mathrm{Ser}^{473}$. We found that while Akt phosphorylation at $\mathrm{Thr}^{308}$ was not affected by the LPS or ghrelin, the LPS-induced suppression in Akt phosphorylation at $\mathrm{Ser}^{473}$ was subject to a partial reversal in the presence of iNOS inhibitor, 1400W and ascorbate, but not the cNOS inhibitor, L-NAME (Figure 7). Fur- 


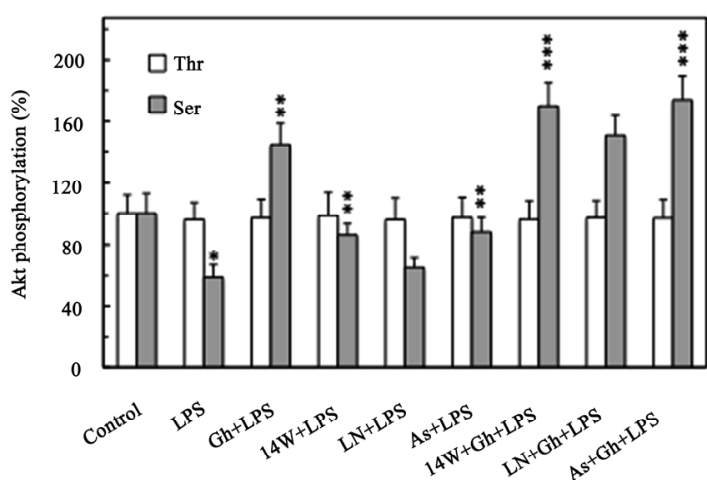

Figure 7. Effect of iNOS inhibitor, $1400 \mathrm{~W}$, cNOS inhibitor, L-NAME, and ascorbate on the ghrelin (Gh)-induced changes in Akt kinase $\mathrm{Thr}^{308}$ and Ser ${ }^{473}$ phosphorylation in the acinar cells exposed to $P$. gingivalis LPS. The cells, preincubated with $30 \mu \mathrm{M}$ 1400W (14W), $200 \mu \mathrm{M}$ L-NAME (LN), or $300 \mu \mathrm{M}$ ascorbate (As), were treated with $\mathrm{Gh}(0.6 \mu \mathrm{g} / \mathrm{ml})$ and incubated for $16 \mathrm{~h}$ in the presence of $100 \mathrm{ng} / \mathrm{ml} \mathrm{LPS}$. $* P<0.05$ compared with that of control. $* * P<0.05$ compared with that of LPS alone. ${ }^{* * *} P<0.05$ compared with that of Gh+LPS.

ther, both ascorbate and 1400W elicited enhancement in the effect of ghrelin on Akt protein phosphorylation at $\mathrm{Ser}^{473}$. These findings indicate that the LPS-induced Akt protein S-nitrosylation exerts the detrimental effect on the kinase activation through phosphorylation at $\mathrm{Ser}^{473}$.

To address further the relationship between Akt S-nitrosylation and its activation through phosphorylation, the acinar cells prior to incubation with P. gingivalis LPS were pretreated with iNOS inhibitor, 1400W or ghrelin, and the lysates following the biotin switch procedure were probed with antibodies directed against phospho-Akt $\left(\mathrm{Ser}^{473}\right)$ and total Akt (Figure 8). We observed that the acinar cells exposed to the LPS alone showed a marked increase in Akt protein S-nitrosylation, while the effect of ghrelin was reflected in the loss in Akt S-nitrosylation and the increase in its protein phosphorylation. Furthermore, the blockage of iNOS activity with $1400 \mathrm{~W}$, lead to a substantial decrease in the LPS-induced Akt S-nitrosylation. Thus, ghrelin countering effect of the detrimental consequences of P. gingivalis LPS on the Akt activity is reflected in a decrease in the kinase protein S-nitrosylation and the increase in its phosphorylation.

\section{Discussion}

The oral mucosal responses to periodontopathic bacterium, $P$. gingivalis and its key virulence factor, cell wall LPS, are manifested by a massive rise in epithelial cell apoptosis, increase in proinflammatory cytokine expression and the disturbances in NO signaling path

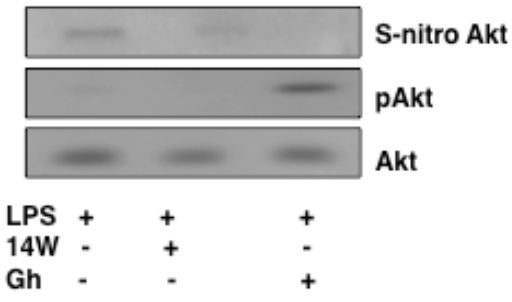

Figure 8. Effect of Ghrelin (Gh) on P. gingivalis LPS-induced Akt S-nitrosylation. The acinar cells were treated with $30 \mu \mathrm{M}$ of iNOS inhibitor, 1400W (14W), or 0.6 $\mu \mathrm{g} / \mathrm{ml} \mathrm{Gh}$, and incubated for $16 \mathrm{~h}$ in the presence of $100 \mathrm{ng} / \mathrm{ml}$ LPS A portion of the cell lysates was processed by biotin switch procedure for protein S-nitrosylation and, along with the reminder of the lysates, subjected to SDS-PAGE, transferred to nitrocellulose and probed with phospho-Akt $\left(\mathrm{Ser}^{473}\right)$ antibody, and after stripping reprobed with anti-Akt antibody. The immunoblots shown are representative of three experiments.

ways $[8,23,29]$. As serine/threonine kinase Akt plays a central role in the regulation of NOS isozyme system responsible for $\mathrm{NO}$ generation $[8,15,23]$, in this study we investigated the processes associated with the activation of Akt in rat sublingual salivary gland acinar cells and the influence of P. gingivalis LPS.

Our findings revealed that the LPS-induced decrease in cNOS activity and up-regulation in iNOS was associated with the suppression in the activity of Akt kinase. Moreover, we found that of the two phosphorylation sites required for the expression of full Akt activity [17, 19], the effect of the LPS was manifested by a decrease in Akt protein phosphorylation at $\mathrm{Ser}^{473}$, whereas phosphorylation at the kinase $\mathrm{Thr}^{308}$ was not affected. These finding are thus in keeping with the literature data indicating that inactivation of Akt by bacterial toxins correlates with the reduced phosphorylation at the kinase $\mathrm{Ser}^{473}$ located within HM region of the C-terminal domain of the kinase $[21,30]$. Further, preincubation with a peptide hormone, ghrelin $(1,2)$, recently identified in saliva and recognized for its modulatory effect on the inflammatory responses to bacterial infection [3-5,7,8], elicited countering effect on the LPS-induced changes in Akt activity and the extent of the kinase phosphorylation on $\mathrm{Ser}^{473}$. Moreover, ghrelin countered the LPSinduced suppression in cNOS activity and elicited reduction in the activity of iNOS. We also observed that in agreement with well documented role of Akt participation in posttranslational cNOS activation through phosphorylation at Ser1179 $[6,7,15]$, the induced up-regulation in cNOS activity by ghrelin was susceptible to sup- 
pression by Akt inhibitor, SH-5. These findings together with the recently demonstrated involvement of Akt in LPS-activated mechanism of iNOS expression induction [31], attest to central role Akt in the regulation of NOS system and add further credence as to the importance of ghrelin in controlling the extent of inflammatory involvement in response to bacterial infection.

Moreover, the accumulating evidence indicates that physiological and pathophysiological implications of NO generated by NOS isozyme system may also involve protein modification through S-nitrosylation at cysteine residues that results in functional alterations $[7,9,16,20,21]$. The NO generated by cNOS has been linked to the inhibition of apoptogenic signal propagation through S-nitrosylation of the key executioner caspase, caspase-3, and the events of cytosolic phospholipase A2 activation [7,22,32]. The NO produced by iNOS, on the other hand, has been implicated in S-nitrosylation of the insulin receptor and proteins involved in early steps of the insulin signal transduction, and Akt S-nitrosylation was reported to be responsible for the reduced kinase activity in muscle cells of diabetic mice $[8,16,20,21]$.

Hence to gain more insights into the mechanism of P. gingivalis LPS-induced disturbances in the acinar cell Akt kinase activation, we examined the effect of cNOS and iNOS inhibitors, as well as nitrosothiols reducing agent, ascorbate, on Akt activity and its protein phosphorylation at the critical $\mathrm{Thr}^{308}$ and $\mathrm{Ser}^{473}$. Our findings revealed that, while phosphorylation at the Akt $\mathrm{Thr}^{308}$ was not affected, the LPS-induced suppression in Akt activity and the extent of its protein phosphorylation at Ser $^{473}$ showed susceptibility to iNOS inhibitor, 1400W, and ascorbate, but not to cNOS inhibitor, L-NAME. Moreover, both 1400W and ascorbate elicited amplification in ghrelin effect on Akt phosphorylation at $\operatorname{Ser}^{473}$ as well the activity. Considering well-known susceptibility of S-nitrosylated proteins to reduction by ascorbic acid $[26,27]$, the presented data support the involvement of iNOS in the acinar cell Akt protein S-nitrosylation and indicate that S-nitrosylation interferes with the kinase activation through phosphorylation at $\mathrm{Ser}^{473}$. It is also apparent, that the countering effect of ghrelin on the LPS-induced changes in Akt activity are reflected in the loss in the kinase S-nitrosylation and the increase in its phosphorylation at $\mathrm{Ser}^{473}$ located within the HM region of the C-terminal domain of Akt [30]. Thus Akt protein S-nitrosylation, like that of its phosphorylation at Ser/Thr, appears to be of significance to a variety of physiological and pathophysiological situations that relay on signaling events which utilize this kinase.

Additional evidence as to the role of ghrelin in countering P. gingivalis LPS interference with Akt activation through S-nitrosylation comes from the results of biotin switch assay. We found that the acinar cells exposed to incubation with the LPS showed a marked increase in Akt protein S-nitrosylation. The countering effect of ghrelin on the LPS-induced suppression in Akt activity was reflected in the loss in S-nitrosylation and the increase in the kinase phosphorylation at $\operatorname{Ser}^{473}$. Moreover, we observed the dependence of Akt S-nitrosylation on the LPS-induced up-regulation in iNOS activity, as the suppression of iNOS with a specific inhibitor, 1400W, lead to a substantial decrease in Akt S-nitrosylation. These results are thus indicative of the involvement of iNOS-generated NO in the suppression of Akt activity through S-nitrosylation. Hence, the persistent induction in iNOS may be of major consequence defining the extent of oral mucosal inflammatory involvement in response to $\mathrm{P}$. gingivalis infection.

Together, the data provided in our study demonstrate that P. gingivalis LPS-induced up-regulation in the acinar cell iNOS expression leads to Akt inactivation through S-nitrosylation that exert the detrimental effect on cNOS activation through phosphorylation. We also show that the countering effect of ghrelin on the LPS-induced disturbances in Akt kinase activity are manifested in a decrease in the kinase protein S-nitrosylation and the increase in its phosphorylation at Ser ${ }^{473}$.

\section{REFERENCES}

[1] Kojima, M., Hosoda, H., Date, Y., Nakazato, M., Matsuo, H. and Kangawa, K. (1999) Ghrelin is a growth-hormone-releasing acylated peptide from stomach. Nature, 402, 656-660.

[2] Kojima, M. and Kangawa, K. (2005) Ghrelin: structure and function. Physiology Reviews, 85, 495-522.

[3] Groschl, M., Topf, H.G., Bohlender, J., Zenk, J., Klussmann, S., Dotsch, J., Rascher, W. and Rauh, M. (2005) Identification of ghrelin in human saliva: production by the salivary glands and potential role in proliferation of oral keratinocytes. Clinical Chemistry, 51, 997-1006.

[4] Osawa, H., Nakazato, M., Date, Y., Kita, H., Ohnishi, H., Ueno, H., Shijya, T., Satoh, K., Ishino, Y. and Sugato, K. (2005) Impaired production of gastric ghrelin in chronic gastritis associated with Helicobacter pylori. Journal of Clinical Endocrinology \& Metabolism, 90, 10-16.

[5] Waseem, T., Duxbury, M., Ito, H., Ashley, S.W. and Robinson, M.K. (2008) Exogenous ghrelin modulates release of proinflammatory and anti-inflammatory cytokines in LPS-stimulated macrophages through distinct signaling pathways. Surgery, 143, 334-342.

[6] Xu, X., Jhun, B.S., Ha, C.H. and Jin, Z.G. (2008) Molecular mechanisms of ghrelin-mediated endothelial nitric-oxide synthase activation. Endocrinology, 149, 4183-4192.

[7] Slomiany, B.L. and Slomiany, A.(2010) Ghrelin protection against lipopolysaccharide-induced gastric mucosal cell apoptosis involves constitutive nitric oxide syn- 
thase-mediated caspase-3 S-nitrosylation. Mediators of Inflammation, Doi:10.1155/2010/280464.

[8] Slomiany, B.L. and Slomiany, A. (2010) Suppression by ghrelin of Porphyromonas gingivalis-induced constitutive nitric oxide synthase S- nitrosylation and apoptosis in salivary gland acinar cells. Journal of Signal Transduction, Doi:1155/2010/643642.

[9] Korhonen, R., Lahti, A., Kankaanranta, H. and Moilanen, E. (2005) Nitric oxide production and signaling in inflammation. Current Drug Targets: Inflammation \& Allergy, 4, 471-479.

[10] Cuzzocrea, S. and Salvemini, D. (2007) Molecular mechanisms involved in the reciprocal regulation of cyclooxygenase and nitric oxide synthase enzymes. Kidney International, 71, 290-297.

[11] Kim, Y.M., Talanian, R.V. and Billiar, T.R. (1997) Nitric oxide inhibits apoptosis by preventing increases in caspase-3-like activity via two distinct mechanisms. Journal of Biological Chemistry, 272, 31138-31148.

[12] Chanvorachote, P., Nimmannit, U., Wang, L., Stehlik, C., Lu, B., Azad, N. and Rojanaskul, Y. (2005) Nitric oxide negatively regulates Fas CD95-induced apoptosis through inhibition of ubiquitin-proteosome-mediated degradation of FLICE inhibitory protein. Journal of Biological Chemistry, 280, 2044-42050.

[13] Wong, J.M. and Billiair, T.R. (1995) Regulation and function of inducible nitric oxide synthase during sepsis and acute inflammation. Advances in Pharmacology, 34, $155-170$

[14] Slomiany, B.L., Piotrowski, J. and Slomiany, A. (1998) Induction of caspase-3 and nitric oxide synthase-2 during gastric mucosal inflammatory reaction to helicobacter pylori lipopolysaccharide. Biochemistry and Molecular Biology International, 46, 1063-1070.

[15] Haynes, M.P., Li, L., Sinha, D., Russell, K.S., Hisamoto, K., Baron, R., Collinge, M., Sessa, W.C. and Bender, J.R. (2003) Src kinase mediates phopsphtidylinositol 3-kinase /Akt-dependent rapid endothelial nitric-oxide synthase activation by estrogen. Journal of Biological Chemistry, 278, 2118-2123.

[16] Carvalho-Filho, M.A., Ueno, M., Carvalheira, J.B.C., Velloso, L.A. and Saad, M.J.A. (2006) Targeted disruption of iNOS prevents LPS-induced Snitrosylation of IRB/IRS-1 and Akt and insulin resistance in muscle of mice. American Journal of Physiology Endocrinology and Metabolism, 291, E476-482.

[17] Hanada, M., Feng, J. and Hemmings, B.A. (2004) Structure, regulation and function of PKB/AKT - a major therapeutic target. Biochimica et Biophysica Acta-Proteins \& Proteomics, 1697, 3-16.

[18] Lodeiro, M., Theoderopoulous, M., Pardo, M., Casanueva, F.F. and Camina, J.P. (2009) c-Src regulates Akt signaling in response to ghrelin via $\beta$-arrestin signaling-independent and -dependent mechanisms. PLOS ONE, 4, e4686.

[19] Yang, J., Cron, P., Thompson, V., Good, V.M., Hess, D., Hemmings, B.A. and Bradford, D. (2002) Molecular mechanisms for the regulation of protein kinase B/Akt by hydrophobic motif phosphorylation. Molecular Cell 9,
1227-1240.

[20] Yasukawa, T., Tokunaga, E., Ota, H., Sugita, H., Martyn, J.A.J. and Kaneki, M. (2005) S-nitrosylation-dependent inactivation of Akt/protein kinase B in insulin resistance. Journal of Biological Chemistry, 280, 7511 -7518.

[21] Carvalho-Filho, M.A., Ueno, M., Hirabara, S.M., Seabra, A.B., Carvalheira, J.B.C., de Oliveira, M.G., Vellosa, L.A., Curi, R. and Saad, M.J.A. (2005) Snirosation of the insulin receptor, insulin receptor substrate 1 , and protein kinase B/Akt. Diabetes, 54, 959-967.

[22] Slomiany, B.L. and Slomiany, A. (2010) Mechanism of cytosolic phospholipase $A_{2}$ activation in ghrelin protection of salivary gland acinar cell against ethanol cytotoxicity. Advances in Pharmacological Sciences, doi: 10.1155/2010/ 269274.

[23] Slomiany, B.L. and Slomiany, A. (2003) Activation of peroxisome proliferator-activated receptor g impedes porphyromonas gingivalis lipopolysaccharide interference with salivary mucin synthesis through phosphatidylinositol 3-kinase/ERK pathway. Journal of Physiology and Pharmacology, 54, 3-15.

[24] Slomiany, B.L., Murty, V.L.N., Piotrowski, J., Liau, Y.H. and Slomiany, A. (1993) Gycosulfatase activity of P. gingivalis, a bacterium associated with periodontal disease. Biochemistry and Molecular Biology International, 29, 973-980.

[25] Wagner, D.A., Glogowski, J., Skipper, P.L., Wishnok, J.S. and Tannenbaum, S.R. (1982) Analysis of nitrate, nitrite and $[15 \mathrm{~N}]$ nitrate in biological fluids. Analytical Biochemistry, 126,131-138.

[26] Jaffrey, S.R., Erdjument-Bromage, H., Ferris, D., Tempst, P. and Snyder, S.H. (2001) Protein S-nitrosylation: a physiological signal for neuronal nitric acid. Nature Cell Biology, 3, 193-197.

[27] Forrester, M.T., Forrester, M.W. and Stamler, J.S. (2007) Assessment and application of the biotin switch technique for examining protein S-nitrosylation under conditions of pharmacologically induced oxidative stress. Journal of Biological Chemistry, 282, 13977-13983.

[28] Slomiany, B.L. and Slomiany, A. (2008) Leptin protection of salivary gland acinar cells against ethanol cytotoxicity involves Src kinase-mediated parallel activation of prostaglandin and constitutive nitric oxide synthase pathways. Inflammopharmacology, 16, 76-82.

[29] Wang, P.L. and Ohura, K. (2001) Porphyromonas gingivalis lipopolysaccharide signaling in gingival fibroblastsCD14 and toll-like receptors. Critical Reviews in Oral Biology and Medicine, 13,132-142.

[30] Wiles, T.J., Dhakal, B.K., Eto, D.S. and Mulvey, M.A. (2008) Inactivation of host Akt/PKB signaling by bacterial pore-forming toxins. Molecular Biology of the Cell, 19, 1427-1438.

[31] Hattori, Y., Hattori, S. and Kasai, K. (2003) Lipopolysaccharide activates Akt in vascular smooth muscle cells resulting in induction of inducible nitric oxide synthase through nuclear factor-kappa B activation. European Journal of Pharmacology, 481, 153-158.

[32] Mannick, J.B. (2007) Regulation of apoptosis by protein S-nitrosylation. Amino Acids, 32, 523-526. 